\title{
Rare earth oxide tracking coupled with 3D soil surface modelling: an opportunity to study small-scale soil redistribution
}

\author{
Judit Alexandra Szabó ${ }^{1,2}$ (1) $\cdot$ Csilla Király $^{1} \cdot$ Máté Karlik $^{3} \cdot$ Adrienn Tóth $^{1} \cdot$ Zoltán Szalai $^{1,2} \cdot$ Gergely Jakab $^{1,2,4}$
}

Received: 1 September 2019 / Accepted: 3 February 2020 / Published online: 12 March 2020

(C) The Author(s) 2020

\begin{abstract}
Purpose Small-scale runoff and soil redistribution processes are important factors in rainfall simulation studies. Therefore, the main objective of this study is to examine the feasibility of rare earth oxide (REO) tracking combined with 3D surface modelling and soil crust analysis by scanning electron microscopy.

Materials and methods Four $40 \mathrm{mmh}^{-1}$ rainfall simulations (divided into two blocks) were conducted on a Luvisol sample at 9\% slope steepness. In a block, two successive simulations were run on a tilled, and then, on a crusted surface. Before the first rainfall simulation of a block, the tilled surface was prepared by hoeing and application of four REO tracers $\left(\mathrm{Pr}_{6} \mathrm{O}_{11} \mathrm{Sm}_{2} \mathrm{O}_{3}, \mathrm{Ho}_{2} \mathrm{O}_{3}\right.$ and $\mathrm{Yb}_{2} \mathrm{O}_{3}$ ) to the freshly tilled surface. REOs divided the parcel into two back, and two front sub-parcels. The REO runoff content was measured by XRF, while the redistributed REOs were measured by SEM on polished crust samples taken after the second experiment in each block. Additionally, before and after 3D models of the surface were created for determining runoff direction and redistribution pattern.

Results and discussion According to the REO content of the soil loss samples, the soil washed down from the front sub-parcels, while back parcels started contributing to soil loss only during the second block experiments. The surface microtopography changed between the experiments. The runoff path from the back sub-parcels headed to one side of the parcel. This strong, crossside runoff pattern explained the lack of the back sub-parcel REOs in the soil loss. Meanwhile, in the crust samples, several forms of the redistribution were identified. The REOs of the back sub-parcels were found in the samples that were collected in runoff paths, and the leaching pattern became traceable with REOs. Moreover, we were able to reconstruct the original surface easily on SEM images.

Conclusions Small-scale redistribution and the role of the microtopography of the surface should be considered as an erosional factor in erosion studies in a more detailed way. Behaviour of the REO as a soil sediment tracer has great potential, although questions remain. REO tracing applied with runoff direction modelling and SEM analysis of soil crust samples was suitable to monitor the runoff path, and explain the soil redistribution pattern horizontally and vertically.
\end{abstract}

Keywords Erosion tracking $\cdot$ Rear earth oxide $\cdot$ Soil erosion $\cdot$ Soil redistribution

Responsible editor: Dong-Mei Zhou

Judit Alexandra Szabó

szabo.judit@csfk.mta.hu

1 Geographical Institute, Research Centre for Astronomy and Earth Sciences, Budapest 1112, Hungary

2 Department of Environmental and Landscape Geography, Eötvös Loránd University, Budapest, Hungary

3 Institute for Nuclear Research, Debrecen, Hungary

4 Institute of Geography and Geoinformatics, University of Miskolc, Miskolc, Hungary

\section{Introduction}

The organic matter and nutrient-rich topsoil loss and redistribution are serious issues for agricultural fields. During the process of inter-rill erosion, aggregates break down due to raindrop impact, and detached soil material is transported and deposited according to the energy of the overland flow (Hairsine and Rose 1991; Kinnell 2005; Balacco 2013; Zhang and Wang 2017). The volume of the total soil loss on the field or watershed scale has been one of the main questions of past decades. Hence, several models and equations were evaluated (Wischmeier and Smith 1978; Morgan et al. 1998; Flanagan and Nearing 1995) to quantify current understanding. Nevertheless, these 
spatially and temporally averaged soil loss values are unable to provide information about the main source areas and are not capable of tracking the redistribution of sediment through a field or a watershed. For example, according to Polyakov et al. (2004), the sediment leaves the watershed mostly during short-duration, high-intensity storms.

During soil transportation and redistribution, surface roughness conditions determine drainage network development on the surface. Flow concentrates into a decreasing number of flow paths with deeper incisions on the smooth surface, while on rough surfaces the number of flow paths increase compared to the initial conditions (Römkens et al. 2002). This morphological development of the surface is the visible evidence of the soil redistribution; in general, previously detached particles move to lower areas and accumulate in microdepressions. As Szalai et al. (2016) reported, soil loss and sedimentation often occur on the same geomorphological (slope) position simultaneously, even during the same precipitation event. However, the average sediment travelling distances or other redistribution processes within a watershed are still under studied. Change in the characteristics of runoff and decreasing infiltration rates (Le Bissonnais et al. 1989) are consequences of the surface evolution and soil redistribution, including the process of soil sealing (Assouline and Ben-Hur 2006). Additionally, smooth, crusted surfaces increase the runoff velocity, and rough surfaces result in higher water-storage capacity, which delays runoff (Gómez and Nearing 2005).

The development of GIS systems and computer vision techniques allowed easier, faster and more accurate surface 3D modelling. By the comparison of before- and after precipitation stages, high-resolution ( vertical $0.5<\mathrm{mm}$, horizontal $1<\mathrm{mm}$ ) surface digital elevation models (DEMs) of the morphological development are accurately measurable (Shi et al. 2017). The close range digital photogrammetry applied with the structure from motion (SfM) method (Snavely et al. 2008) is a widespread technique for soil-surface modelling (Castillo et al. 2012; Eltner et al. 2013). The SfM method differs from 'classical' stereo pair-based processing, since in the case of $\mathrm{SfM}$, several images are needed, and the camera parameters such as location, geometry and orientation are computed from the images themselves. For small plots $\left(<1 \mathrm{~m}^{2}\right)$, cheaper standard cameras, or mobile phones could be enough to generate a high-resolution DEM.

Not only is the surface change detectable but also the sediment movement is traceable with different methods. According to Knaus and van Gent (1989) and Zhang et al. (2001), the ideal tracer would have the following characteristics: (a) form strong bonds and good integration with soil particles or be easily incorporated into soil aggregates, (b) be insoluble or low-soluble in water, (c) have high analytical sensitivity, (d) be easy and inexpensive to quantify, (e) have low background concentration in soils, (f) have no interference with sediment transport, (g) have low plant uptake and no harm to the eco-environment and (h) be available for multiple tracking. Determining the most suitable tracer is often affected by the scale of the experiment. Different tracers are preferentially used at different scales (Guzmán et al. 2013): in large catchments (>100 ha), natural tracers (fingerprinting methods) (Juracek and Ziegler 2009; Schoonover et al. 2007), and fallout radionuclides (Li et al. 2010; Porto et al. 2011), are dominantly used. Falling radionuclides are also popular in small catchments (di Stefano et al. 1999) and hillslopes (Walling et al. 2009), whereas at the plot scale, rare earth elements (Michaelides et al. 2010; Polyakov and Nearing 2004) and soil magnetism are widely applied (Armstrong et al. 2010; Guzmán et al. 2010). Nevertheless, rare earth oxide (REO) tracking is successfully used in all scales (Deasy and Quinton 2010; Polyakov et al. 2009, 2004; Wei et al. 2003).

REO tracing at the plot scale has many advantages. Rare earth elements are natural elements between 57 and 71 of the periodic table, and they provide multiple tracer opportunities because they have similar geochemical properties with low background concentration in the soil, while also binding strongly to the soil (Zhu et al. 2011). Additionally, they are measurable with different spectroscopic techniques such as inductively coupled plasma-optical emission spectrometry (ICP-OES), inductively coupled plasma mass spectrometry (ICP-MS), energy dispersive X-ray fluorescence (EDXRF), infra-red spectroscopy and neutron activation analysis (NAA) (Zawisza et al. 2011). Disadvantages of REO tracking is that some of the measurement techniques are expensive, destructive, large amounts of REO are needed and the REO leaching into the soil has not been studied. In theory, scanning electron microscopy is also suitable for REO redistribution measurements to survey sediment redistribution. Usually, SEM is used to study soil crust formation (Chen et al. 1980) or the interaction of clay particles (Metzger and Robert 1985) but it has not been employed for REO tracing surface development studies.

The application of REO tracers in soil science mainly focuses on the sediment balance calculation among different landscape positions to identify sediment source and depositional areas. The investigated scale is generally the field scale including small watersheds (Deasy and Quinton 2010; Polyakov et al. 2004) or agricultural hillslopes (Zhu et al. 2011). In these field experiments, the REO tracer is placed on highlighted points of the surface or dispersed homogeneously. In order to calculate the redistributed soil amount, REO is needed to be homogenized in the uppermost soil layer using various mixing procedures (Zhang et al. 2001; Polyakov et al. 2004). Beside the field experiments, plot scale laboratory flume experiments are also carried out to study the erosion dynamic of slope positions (Zhang et al. 2003). Moreover, REO is suitable to track soil aggregate dynamics (Peng et al. 2017), or to trace pedogenic processes in general (Laveuf and Cornu 2009). 
The objectives of this study are to examine the feasibility of using REO tracking combined with 3D surface modelling and crust sampling to explore the potential of using this technique for studying small-scale redistribution. The main questions are:

- Is the path of the runoff and sediment traceable?

- Is there any correlation between the changing contribution area and changing soil loss?

- Is slope steepness or surface morphology the more dominant factor during the runoff path development?

- Is SEM suitable for surface development and soil redistribution studies?

\section{Material and methods}

\subsection{Experimental setup}

The rainfall simulator experiments were carried out in the Eötvös Loránd University, Budapest. The laboratory scale simulator has a $0.5 \times 1 \mathrm{~m}$ flume equipped with parallel runoff collector outlets. The flume was filled with a haplic Luvisol collected from the cultivated layer of the Szentgyörgyvár experimental plot of the Geographical Research Institute, Research Centre for Astronomy and Earth Sciences (Madarász et al. 2011), modelling a recently cultivated soil structure. The flume was set at $9 \%$ slope steepness. Then, the soil sample was compacted with two successive 20-min (27 mm) rainfall simulations. For raindrop construction, a Lechler 460.788 full-cone nozzle at $21 \mathrm{kPa}$ pressure was used, which provided a constant $40 \mathrm{~mm} \mathrm{~h}^{-1}\left(\mathrm{KE}=18 \mathrm{~J} \mathrm{~m}^{-2} \mathrm{~mm}^{-1}\right)$ intensity (Salles et al. 1999).
Four REO tracers, namely $\operatorname{Pr}_{6} \mathrm{O}_{11}, \mathrm{Sm}_{2} \mathrm{O}_{3}, \mathrm{Ho}_{2} \mathrm{O}_{3}$ and $\mathrm{Yb}_{2} \mathrm{O}_{3}$, were selected for the study. Most REO tracking studies used $\mathrm{Pr}_{6} \mathrm{O}_{11}, \mathrm{Nd}_{2} \mathrm{O}_{3}, \mathrm{Sm}_{2} \mathrm{O}_{3}, \mathrm{La}_{2} \mathrm{O}_{3}$ and $\mathrm{Gd}_{2} \mathrm{O}_{3}$ (Deasy and Quinton 2010; Polyakov and Nearing 2004; Zhang et al. 2001, 2003); however, our choice to use $\mathrm{Ho}_{2} \mathrm{O}_{3}$ and $\mathrm{Yb}_{2} \mathrm{O}_{3}$ in addition to $\operatorname{Pr}_{6} \mathrm{O}_{11}$ and $\mathrm{Sm}_{2} \mathrm{O}_{3}$ was based on pre-tested separability of the X-ray fluorescence (XRF) curves of the REOs. Moreover, $\mathrm{Ho}_{2} \mathrm{O}_{3}$ and $\mathrm{Yb}_{2} \mathrm{O}_{3}$ have the lowest concentrations $\left(<1 \mathrm{mg} \mathrm{kg}^{-1}\right)$ in natural soils (Kabata-Pendias and Pendias 2001). The particle-size distribution of the REO powders (Treibacher Industrie) were measured with a Fritch Laser Particle Sizer Analysette 22 Microtech Plus using Fraunhofer theory for calculation. Median diameters of the tracers were 5.16, 2.41, 3.98 and $1.82 \mu \mathrm{m}$ for $\operatorname{Pr}_{6} \mathrm{O}_{11}$, $\mathrm{Ho}_{2} \mathrm{O}_{3}, \mathrm{Yb}_{2} \mathrm{O}_{3}$ and $\mathrm{Sm}_{2} \mathrm{O}_{3}$, respectively.

The experimental design was compiled into two blocks, and in each block two rainfall simulations were performed (Fig. 1). Before the first rainfall simulation of a block, the tilled surface was prepared by hoeing and the four REO tracers were applied to the freshly tilled surface. To determine the limit of detection (X-ray fluorescence), various concentrations were tested on soil samples previously. Consequently, $5 \mathrm{~g}$ REO were mixed with $20 \mathrm{ml}$ distilled water and spread on a subplot $\left(0.125 \mathrm{~m}^{2}\right)$ surface applying the spraying technique of Deasy and Quinton (2010) to tag the surface with REO. This method caused minimal surface disturbance and ensured full coverage. The plot area was divided to four sub-parcels (left back ( $\mathrm{LB})-\mathrm{Pr}_{6} \mathrm{O}_{11}$; right back $(\mathrm{RB})-\mathrm{Sm}_{2} \mathrm{O}_{3}$; left front (LF) $-\mathrm{Ho}_{2} \mathrm{O}_{3}$ and right front ( $\left.\mathrm{RF}\right)-\mathrm{Yb}_{2} \mathrm{O}_{3}$ ) (Fig. 2a).

During the first rainfall, the surface roughness decreased and the crust evolved. After $24 \mathrm{~h}$ drying, the second rainfall simulation of the block was conducted on the crusted surface. Four crust samples were collected after the second two
Fig. 1 Block experiment flow chart
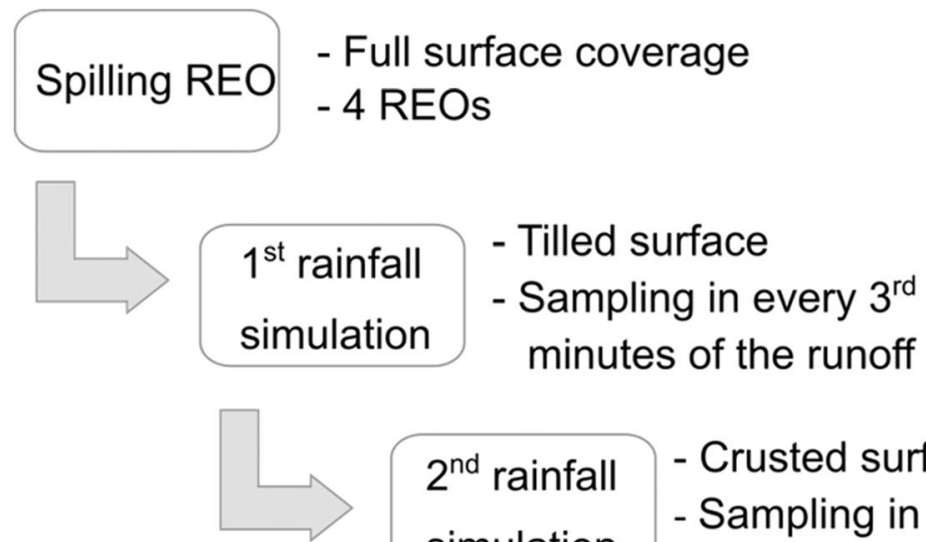

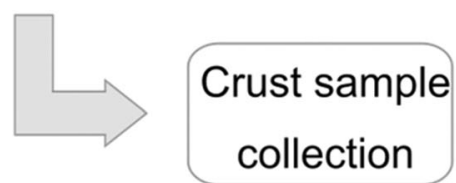


Fig. 2 Sketch of initial REO distribution on the surface (a) and the location of the presented crust samples of block 2 (b). $\mathrm{Pr}-$ $\mathrm{Pr}_{6} \mathrm{O}_{11} ; \mathrm{Sm}-\mathrm{Sm}_{2} \mathrm{O}_{3} ; \mathrm{Ho}-\mathrm{Ho}_{2} \mathrm{O}_{3}$; $\mathrm{Yb}-\mathrm{Yb}_{2} \mathrm{O}_{3} ; L B$ left back subparcel, $R B$ right back sub-parcel, $L F$ left front sub-parcel, $R F$ right front sub-parcel $\mathrm{a}$

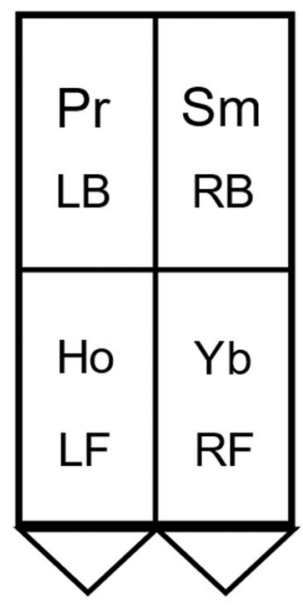

b

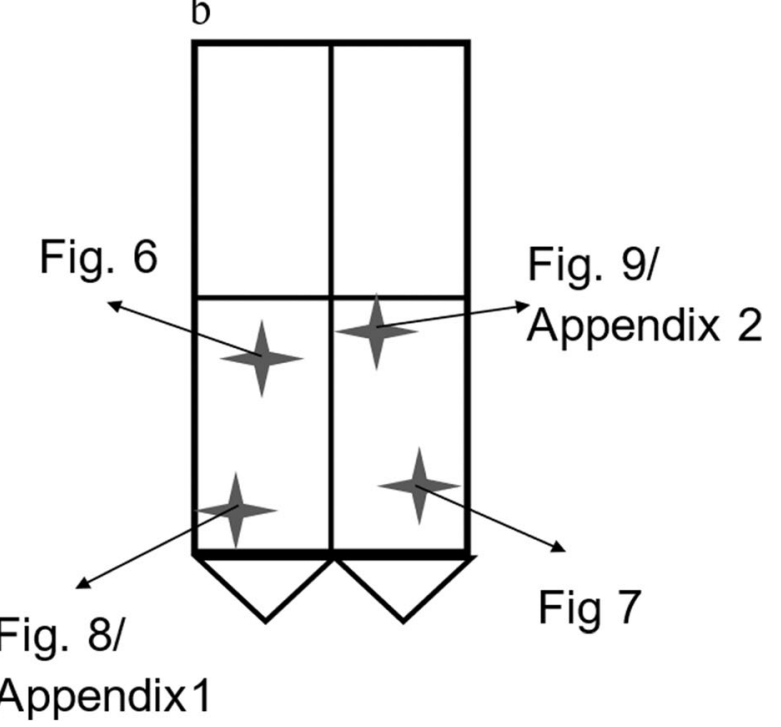

simulations. Those surface spots were selected for crust sampling within the front sub-parcels where both flow route and crust formation were evident, such as in microdepressions. Figure $2 \mathrm{~b}$ shows the location of the crust samples after the block 2, which is presented in the results. After the first block, the uppermost $5 \mathrm{~cm}$ of soil layer was changed to fresh soil, and the experiment was repeated.

The total amount of runoff and sediment were collected at the two outlets separately applying 3-min periods, altogether 12 times after the runoff commenced. A total of 96 runoff (including sediment) samples and 8 crust samples were collected.

The runoff volumes were measured and then dried out in order to identify the sediment volume. Then the changing sediment volumes were compared with measured REO concentrations to test whether they are in direct linkage.

\subsection{REO concentration of the soil loss}

XRF spectroscopy measurements were performed on soil loss samples. The elemental composition was determined with a portable energy dispersive X-ray fluorescence spectrometer (Spectro XSort XHH03, Collimator size $3 \mathrm{~mm}$, Tube type: $\mathrm{Rh}$ anode tube, max voltage: $50 \mathrm{kV}$, maximum output: $2.5 \mathrm{~W}$ ), stabilized with a docking station. The instrument was operated in Environment Method mode, and the total measurement time was $100 \mathrm{~s} /$ measurement. The measurement was non-destructive but the samples were drilled under $63 \mu \mathrm{m}$ to measure the pressed powder. The spectrums were analysed with Analyzer Pro software.

$\mathrm{X}$-ray fluorescence spectroscopy is a non-destructive tool to analyse element compositions of different materials. When a material is exposed to $\mathrm{x}$-ray radiation, the $\mathrm{X}$-ray photons can eject electrons from the shells. If an electron escapes from the shell, vacancies are created and are filled with an electron from a higher energy shell. During this process, the electron releases excess energy in the form of a secondary photon. In the energy-dispersive spectroscopy (EDS-XRF) technique, the instrument detects these secondary photons. The count number of the secondary photons is proportional to the concentration of the elements. The REE elements count number was calculated in the Pr LBeta1 $(5.48 \mathrm{KeV})$, Sm LAlpha1 (5.63 KeV), Yb LBeta1 $(8.4 \mathrm{KeV})$ and Ho LAlpha1 $(6.72 \mathrm{KeV})$ lines, and these lines were selected to not overlap with each other. The net count number is one of the best choices to differentiate REE signals (net count $=$ total count number-background count number) since it is proportional to REE mass. (No factory fundamental parameter calibrations include REE information at this scale.)

\subsection{Spatial redistribution of the REO tracers}

SEM was the second spectroscopy technique used in the study, and it was chosen because REOs are brighter in greyscale electron microscope images since elements with higher atomic numbers are brighter than the elements with lower atomic numbers. The atomic number of the selected REOs were 59, 62, 67 and 70 for $\operatorname{Pr}_{6} \mathrm{O}_{11}, \mathrm{Sm}_{2} \mathrm{O}_{3}, \mathrm{Ho}_{2} \mathrm{O}_{3}$ and $\mathrm{Yb}_{2} \mathrm{O}_{3}$, respectively, which are higher than the atomic number of Si (14), O (8), Mg (12), C (6) or Ca (20), which represent the majority of soil elements.

Soil crust samples were prepared using Epoxy Heat, followed by surface polishing. Then, the texture of soil and REO dispersion was observed by a Hitachi TM4000 Plus scanning electron microscope with EDS detector. During the analysis, the accelerating voltage was $15 \mathrm{kV}$, and the backscattered electron image was used to determine the texture. Approximately $1-2 \mathrm{~cm}^{2}$ per sample was analysed, with 20 30 spectrums generated. 


\subsection{Digital elevation model and flow direction modelling}

Photogrammetry and the SfM (Snavely et al. 2008) algorithm were used to create high resolution digital elevation models (DEMs) of surface changes during the subsequent rainfalls. Three DEMs per block were created modelling the actual surface stages as the initial stage and the surface after the first and second rainfalls. Following the consideration of image acquisition of (Gilliot et al. 2017), the images were taken at the resolution of $4160 \times 3120$ pixels. Multiple (20-25) overlapping images from $1 \mathrm{~m}$ height and from different angles covering the whole surface of the flume were applied as inputs for DEM construction. These settings were suitable to create reliably dense point cloud and digital elevation model from the surface and flume with Agisoft PhotoScan. Before the image acquisition, the flume was adjusted to $0^{\circ}$ to avoid horizontal foreshortening, and the corners of the flume could serve as ground control points. Local coordinate system was used, where the front left corner was considered as the pole point. The common pole point also ensured the comparability of the 3D models reflecting various surface conditions. The root mean square error values of the generated point clouds varied between 0.4 and $0.8 \mathrm{~mm}$, and the derivated 3D models had $1 \mathrm{~mm}$ horizontal resolution.

The hydrological tool in ArcGIS 10.3 was used to calculate flow directions, flow accumulation, and small-scale basins of the surfaces based on the DEMs. Before the hydrological modelling, the slope angle of the surface was restored using a plain, $9^{\circ}$ surface.

In the results - in accordance with the presented crust samples - the surface development of the block 2 is presented.

\section{Results}

\subsection{Changes in runoff volume}

The runoff volume was higher on the crusted than on the tilled surface in both blocks and both sides of the flume (Fig. 3). At

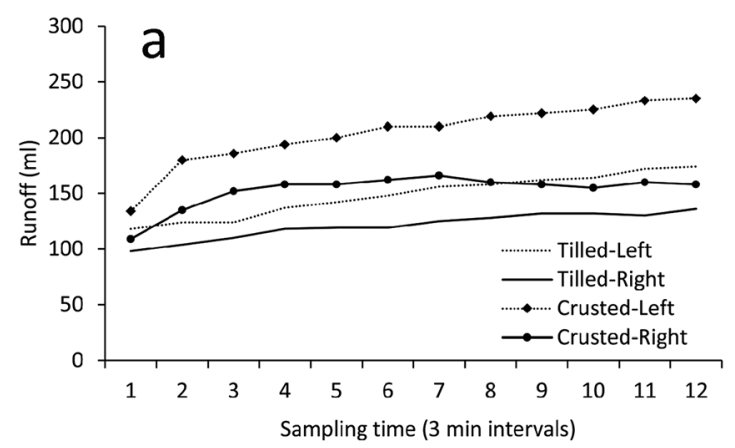

Fig. 3 Runoff volume changes during the experiments in block 1 (a) and block 2 (b). The runoff volume was higher from crusted than tilled surface

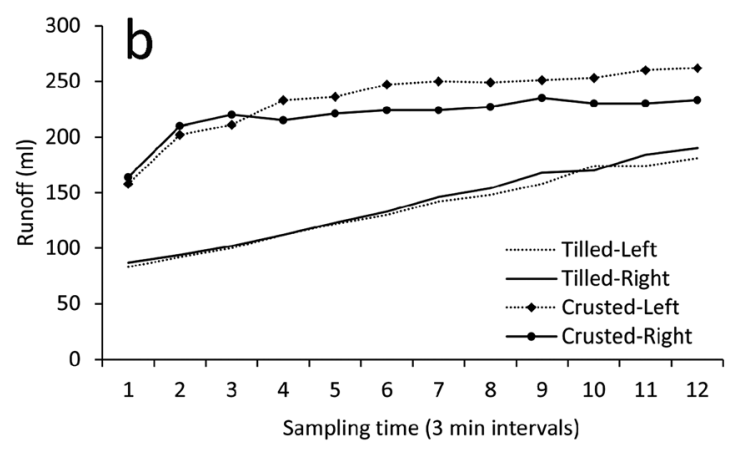

block 1, the difference between the two sides was greater than at block 2, where no difference was found, especially on the tilled surface. The increase in the runoff volume with time was higher on the tilled surface compared to the crusted ones. The maximum runoff was $262 \mathrm{ml}$ in $3 \mathrm{~min}$, while the minimum was $83 \mathrm{ml}$ runoff in $3 \mathrm{~min}$.

\subsection{Soil loss and REO in the runoff}

The amount of soil loss per parcel side was varied with time; however, it generally increased. By contrast, the REO content was decreasing or remained on the same order of magnitude with time in both block and surface, especially in case of the tilled surface (Fig. 4).

No cross-side runoff was detected in block 1 , and the sediment from the back-sub parcel (Pr) reached the collector only during a short period at the end period of the second experiment, when the surface was crusted. In the first experiment, the soil loss of the two sides was equilibrated, and increased more strongly on the right side during the second experiment.

In contrast with the results of block 1 , both cross-side runoff and REO from the back sub-parcels were detected in block 2 (Fig. 4c, d). As a 'flush effect', the pure REOs (without soil interaction) of the front parcels were washed down in the first 9 (right side)-15 min (left side) of the first rainfall of block 2 (Fig. 4a, c). At the end of the first rainfall, the REO concentration from the front parcels reached a constant level of the runoff of the second rainfall (Fig. 4b, d). In spite of the low concentration of $\mathrm{Yb}$ in the runoff from the left side and $\mathrm{Ho}$ in the runoff from the right side, this is an evidence of the crossside runoff (Fig. 4c). In the second half of the second experiment, Sm also appeared in the runoff (Fig. 4d), transferred from the RB sub-parcel, and the soil loss profile began oscillating. The soil loss and its REO content showed no correlation $\left(R^{2}=0.1338\right)$.

\subsection{Flow direction}

The changes in soil surface owing to the rainfalls are barely detectable in the 3D surface models (Fig. 5a-c) even 

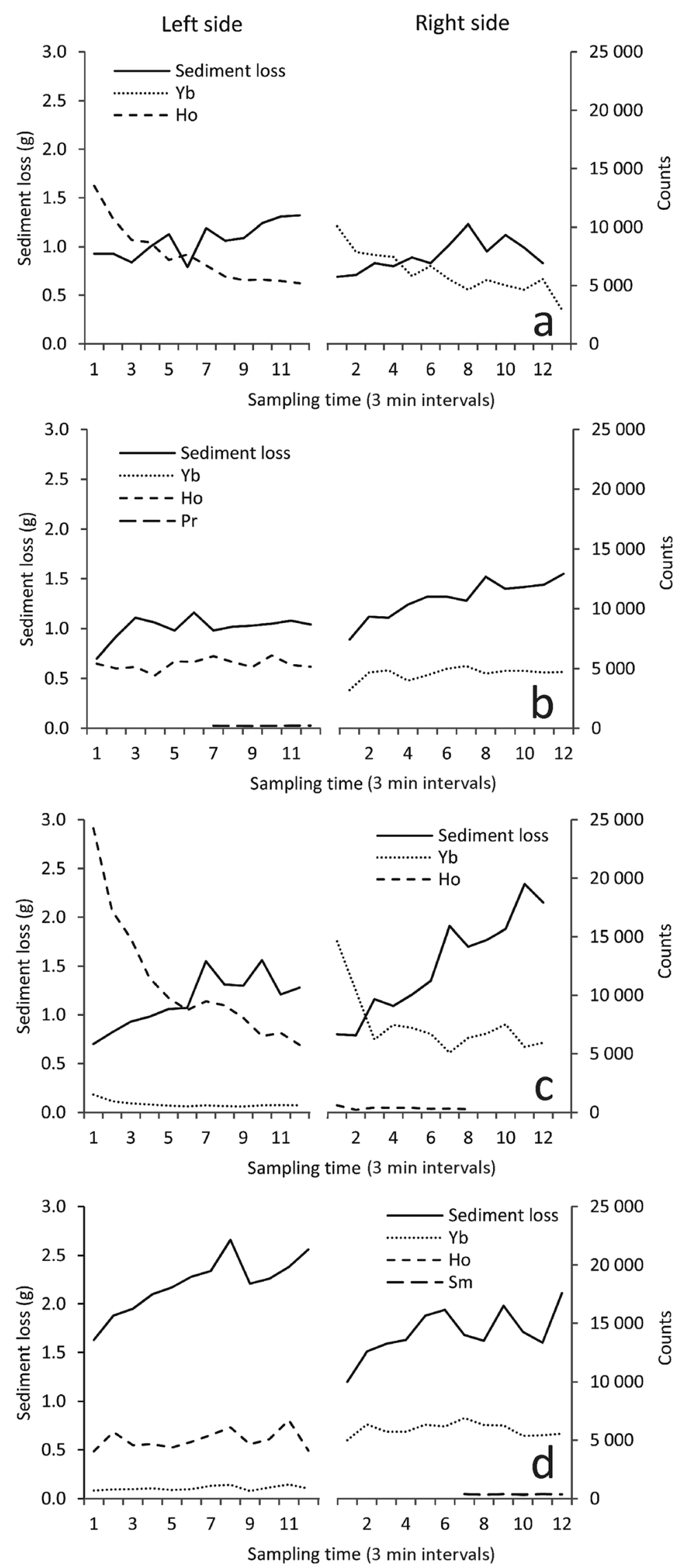

Fig. 4 Sediment and REO dynamics during the experiments. Block 1 (a, b) and block 2 (c, d). g: gram $\mathrm{Pr}-\mathrm{Pr}_{6} \mathrm{O}_{11} ; \mathrm{Sm}_{-}-\mathrm{Sm}_{2} \mathrm{O}_{3} ; \mathrm{Ho}_{-}-\mathrm{Ho}_{2} \mathrm{O}_{3} ; \mathrm{Yb}_{-}-\mathrm{Yb}_{2} \mathrm{O}_{3}$ 
Fig. 5 Surface, flow direction and runoff contribution area changes in block 2 before the first simulation $(\mathbf{a}, \mathbf{d}, \mathbf{g})$, between the two simulations $(\mathbf{b}, \mathbf{e}, \mathbf{h})$ and after the second simulation $(\mathbf{c}, \mathbf{f}, \mathbf{i})$ Both the flow direction and contribution area explain the cross-runoff of Ho
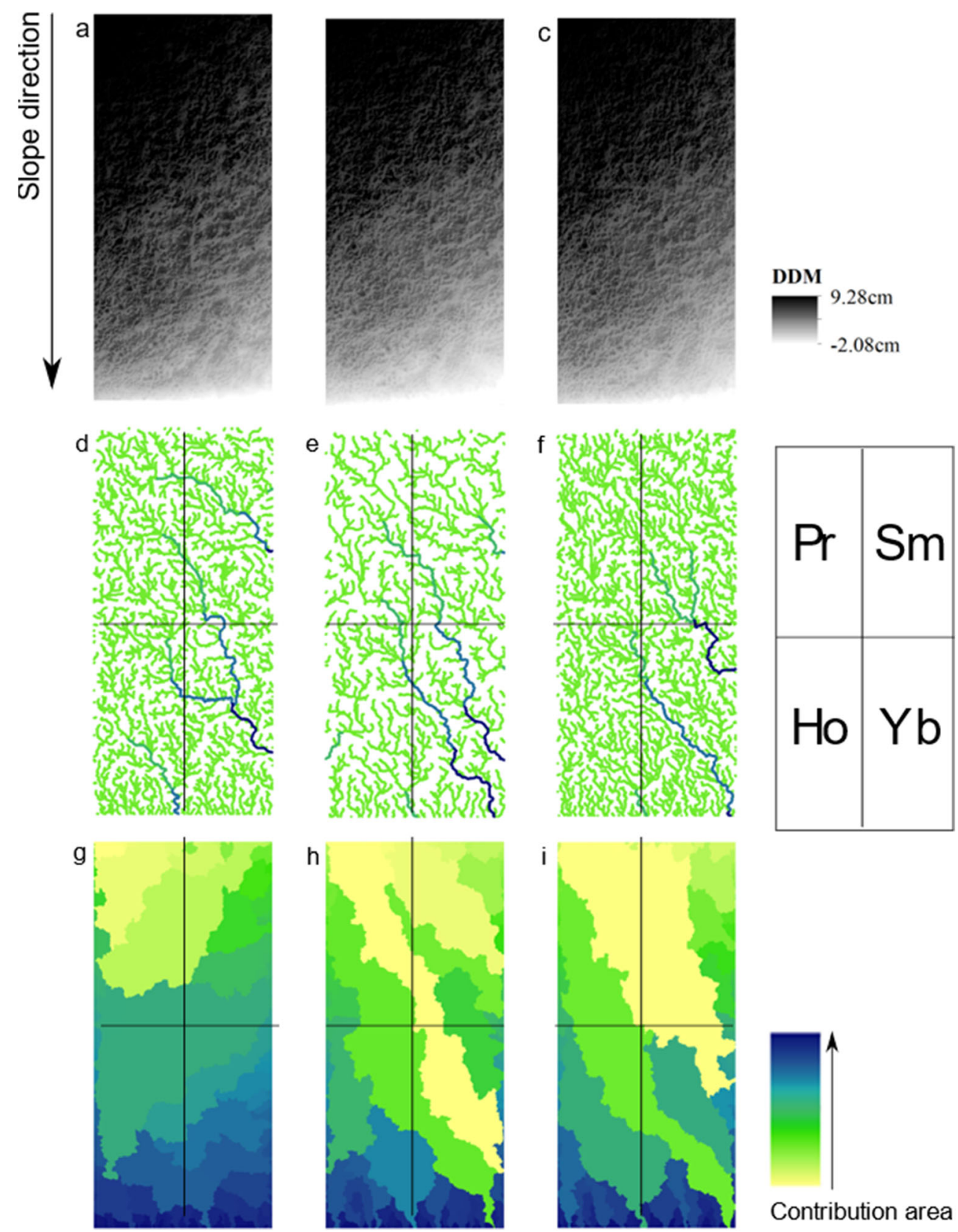

Contribution area though the changes in the runoff pattern are obvious (Fig. 5d-i) in block 2. The prediction of runoff directions based on the initial surface showed a cross-side pattern with a strong leakage on the right side (Fig. 5d) of the parcel supplied by the large 'basin' located in the middle of the parcel (Fig. $5 \mathrm{~g}$ ). This pattern was changed due to the first rainfall (Fig. 5e, h), as the basins were fragmented and the main flow paths emerged. Finally, the rainfall resulted in a moderate union of fragmented parts on the crusted surface. In this case, the main runoff direction (LB to RF) did not change, but the flow became less concentrated (Fig. 5f, i). Close to the sample collector, many pouring points were working, and the largest contribution area coming from one directly on the border of the two sides.

\subsection{Results of scanning electron microscopy}

The crust samples revealed the structure, morphology and compounds of the crust layer as well as provided information about parcel-scale redistribution directions. Structure of the upper 3-4 $\mathrm{mm}$ layer, the REO redistribution pattern on the surface (Figs. 6 and 7) and compounds in deeper areas (Figs. 8 and 9) were measured with scanning electron microscopy. Composite-images mosaics using 3-4 images 
Fig. 6 Crust sample parts from the upper part of block 2, LF subparcel. Blue arrows point to the location of the original surface, which is visible due to the brightness of REOs in SEM images. Pr washed down from the LB sub-parcel to the LF subparcel
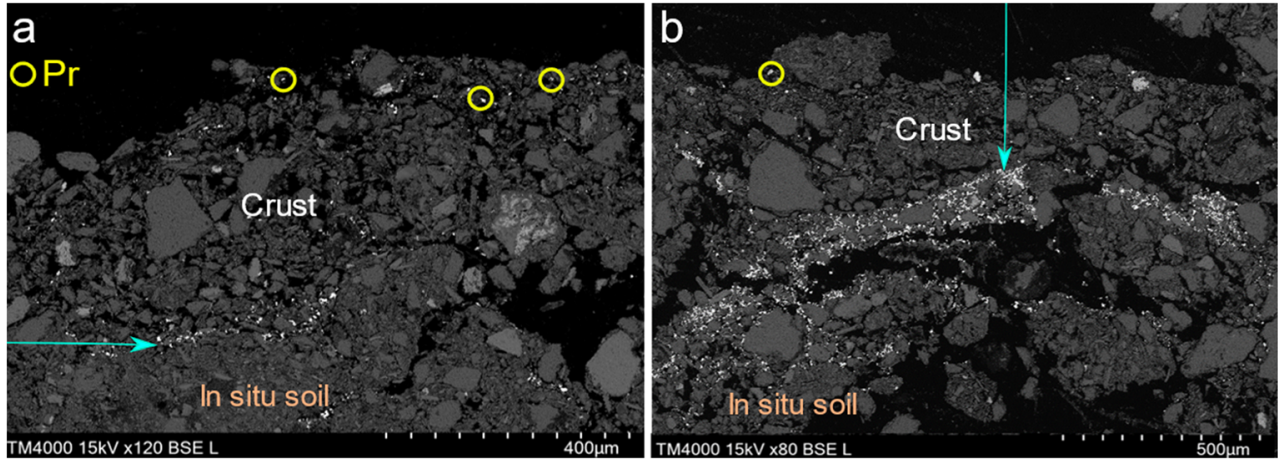

(Appendix 1 and 2) were created to better understand the REO distribution by depth.

\subsubsection{REO on the surface}

REO redistribution among the sub-parcels occurred in two main directions. The LB sub-parcel contribution to runoff was identified as Pr powder and was measured at different parts in the crust sample of the LF sub-parcel 3-400 $\mu \mathrm{m}$ above the initial surface indicated by a high concentration of continuous Ho presence (Fig. 6a, b). Cross-side runoff identified as Ho particles was measured above the $\mathrm{Yb}$ of the RF sub-parcel (Fig. 7).

In both Fig. 6a and b, the crust and in situ soil fraction can be separated visually. In Fig. 6a, the line of the initial surface can be followed (blue arrow) because a quasi-high concentration of Ho had been ejected and remained there, concentrated in microdepressions. The width of the evolved crust and hence the redistribution depth was around $500 \mu \mathrm{m}$. Another visual observation is that the particle distribution in the crust layer was less dense than in the in situ soil, where the organic matter and clay content formed a denser, aggregated structure. The third evidence of LB parcel sediment loading is that some $\mathrm{Pr}$ was measured among the quartz and feldspar soil particles. In

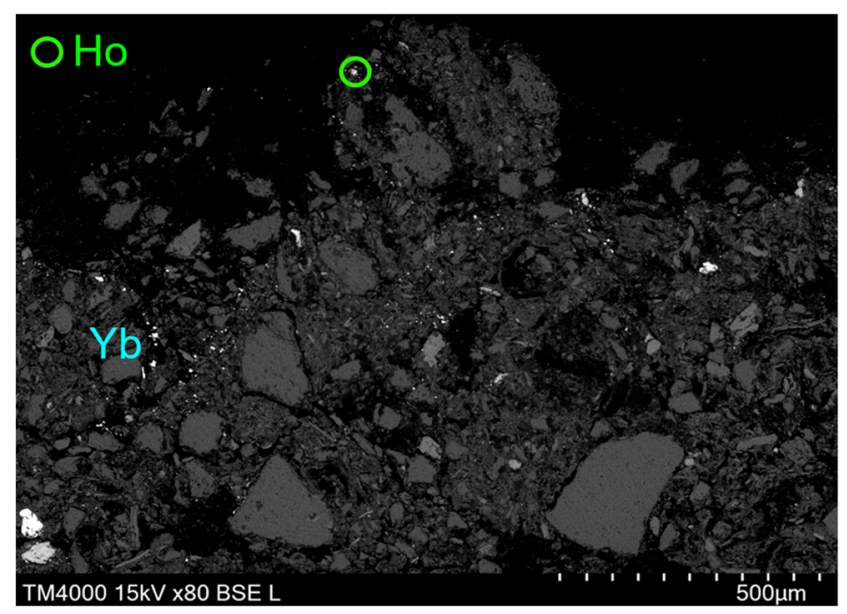

Fig. 7 Crust sample from block 2, RF sub-parcel. The Ho washed down in a cross sub-parcel direction during the runoff other parts of the crust, Ho was more visible (Fig. 6b) and the leaching pattern was observable.

$\mathrm{Yb}$ powder fragmented more than Ho; however, the line of the initial surface was still visible (Fig. 7). In Fig. 7, the structure of the crust and in situ soil is less contrasting than Fig. 6a, b; however, the Ho measured above the $\mathrm{Yb}$ layer was evidence of the cross-side runoff between the front subparcels. The sample was collected close to the border of the two front parcels.

\subsubsection{REO distribution under the surface}

Tracers were also leached into the soil $>2 \mathrm{~mm}$ (Fig. 8) deep. The crust sample in Fig. 8 was collected in a micro depression in the LF sub-parcel. The Ho leached into deeper sections along the macro pore system. The REO concentration decreased gradually with distance from the surface (Appendix 1). In Appendix 1, the full area of the examined crust part and leaching direction pattern is also traceable.

The result containing the most interesting redistribution was found at $4 \mathrm{~mm}$ crust depth of the upper part of the RF sub-parcel (Fig. 9, Appendix 2). Here, in addition to Ho, Pr and $\mathrm{Sm}$ particles were also measured. The location of the sample is close to both sub-parcels (Fig. 2b) and hence the

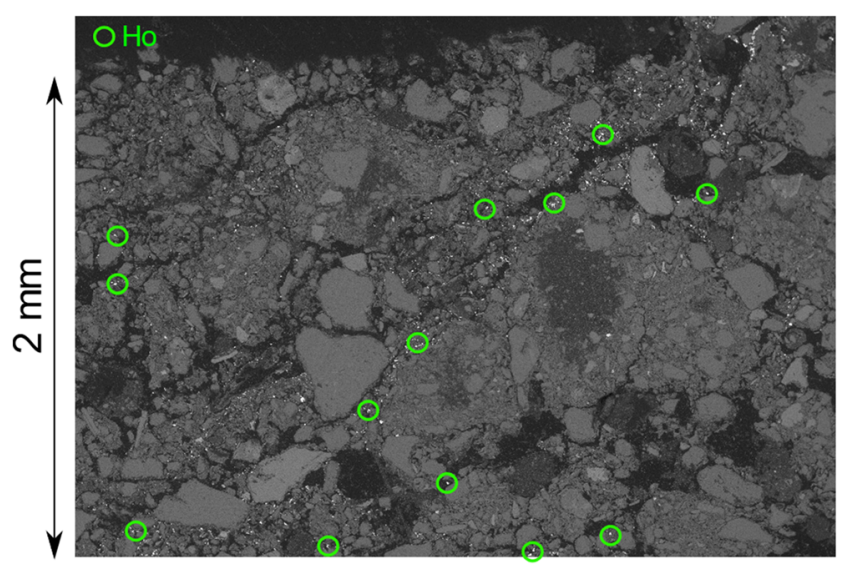

Fig. 8 Leaching pattern marked with Ho particles under a microdepression of the LF sub-parcel on an SEM image 


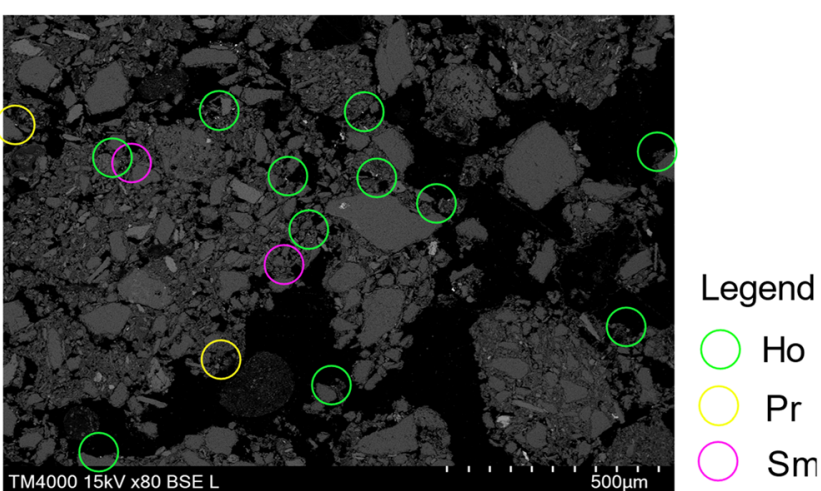

Fig. 9 In situ soil segment at $4 \mathrm{~mm}$ depth on an SEM image. Pr and Sm were found beside the leached Ho

Pr and Sm among the Ho particles probably leached out from the surface.

\section{Discussion}

The microtopography of the surface influences the runoff rate, as the crusted surface reduces infiltration usually induces a higher runoff rate (Assouline and Ben-Hur 2006; GómEZ AND NEARING 2005; SzABÓ et al. 2015). In block 1, there was a minimal difference between the two sides, while in block 2 there was no difference between the sides. This difference can also be attributed surface micromorphology. The micromorphology determined the cross-side directional flow on the surface, and a runoff contribution area (Fig. 5) in the nearby sub-parcel border zone made possible the contribution from the neighbouring REO in the soil loss (Fig. 4).

The 3D model and flow direction modelling concentrate on main flow directions and flow paths, providing only gradual stages of the surface development. In this approach, the role of sheet flow is underrepresented, therefore the reliability of the model is the direct function of the resolution and quality of the DDM. Accordingly, comparing the GIS predicted results with analytically measured data is necessary to improve the efficiency of modelling (Florinsky 2016).

The sediment dynamic was altered more than runoff rate. The observed short-term oscillating sediment amounts is, according to Wang and Shi (2015), probably part of the longterm constant trend, and not connected to the evolved runoff area. The sediment dynamic and the REO dynamic had no similarities under the tilled surface, as at runoff initiation the unbound REO powder washed down. Zhang et al. (2001) reported that REO powders mixed with soil were uniformly incorporated with aggregates, and were bound with soil particles while Deasy and Quinton (2010) also published that the calibrated sprayer technique had allowed the solution to bind to the surface. By contrast, Polyakov and Nearing (2004) reported sediment overestimation due to REO enrichment at the beginning of the runoff appearance, which was explained by initial flushing of the poorly incorporated traces as was also found in the present study. This contradiction underlines that more REO tracer studies are needed to test the binding behaviour of this promising tracing method in various topsoils. REO is believed to be attached to the colloid size particles (organic matter, sesquioxides and clay) of the soil (Laveuf and Cornu 2009) even though in practice the relationship is not as simple (Xing and Dudas 1993). The role of aggregation, organic matter composition, tillage and moisture dynamics has also a considerable effect on the method applicability (Peng et al. 2017).

The leaching experiment of Stevens and Quinton (2008) showed no significant REO losses due to leaching, and REO interacted mainly with the soil surface. In our experiments, the crust samples suggest the same behaviour of the REO tracer, and additionally, the REO leached into the soil dominantly in the macro pore system. In Fig. 9, three different REOs were found at $4 \mathrm{~mm}$ depth. This finding also shows that the redistributed material was able to leach into the soil after it was carried by the runoff.

The original surface line reconstructions were straightforward in most crust samples; the spayed REO powder remained on the surface indicating the border between the in situ soil and crust. The average $500-\mu \mathrm{m}$-thick crust structure and redistributed REO from the back-parcel is evidence of redistribution. In each block, only one subparcel REO was measured in the soil loss, but both REOs were identified in the crust samples taken from the front sub-parcel. These findings enhance the impact of the surface or micromorphology on the runoff directions and soil loss as well as the calculation with small-scale redistribution in larger scale models. The structureless, displaced, freely removable particles (Fig. 6a) in the long term (or with the more frequent big storms) will be mobilized easier over longer distances. Currently, their amount is unpredictable. This phenomenon will also intensify sizeselective erosion processes (Wang and Shi 2015) and organic carbon redistribution (Jakab et al. 2018).

Applying the spraying technique of Deasy and Quinton (2010) revealed a new perspective of tracing with REO powders in surface processes in both horizontal (redistribution among sub-parcel) and vertical (crust thickness and leaching) directions. Creating thin sections from the surface is a time-consuming but inexpensive method whose results can be analysed many ways, including traditionally optical microscope (Norton 1987; Valentin and Bresson 1992; Pires et al. 2013), and morphologically directed Raman spectroscopy (Király et al. 2019a, b). Additionally, we found SEM to be a suitable measurement technique for thin section analysis when REO was sprayed on the soil surface. However, this method depends on the sampling design. Since the thin section represents only a small part of the surface, multiple repetitions are needed to adequately describe the redistribution. 


\section{Conclusions}

REO tracing applied with surface modelling and runoff direction modelling, and SEM analysis of crust samples was suitable to follow the path of water runoff, and explain the soil redistribution pattern horizontally and vertically. Intensive erosion and sedimentation were detected parallel, whereas the REOs were useful for soil redistribution estimation, and promising for soil loss value estimation and tracking infiltration in the soil. Small-scale redistribution seems to be independent from the overall slope length and incline emphasizing the role of microtopography. Most of the delivered particles were deposited within decimetres resulting small changes in the original REO pattern. However, the investigation was carried out under unique topographical and soil conditions the sensitivity of this method under various environmental circumstances is not known yet.

Acknowledgements The work was supported by the ÚNKP-18-3 New National Excellence Program of the Ministry of Human Capacities and co-funded by the National Research Development and Innovation Office of Hungary (grant number 123953) A. Tóth was supported by Bolyai János Research Scolarship and PD112729 scholarships.

Funding Information Open access funding provided by MTA Research Centre for Astronomy and Earth Sciences (MTA CSFK).

\section{Appendix 1}

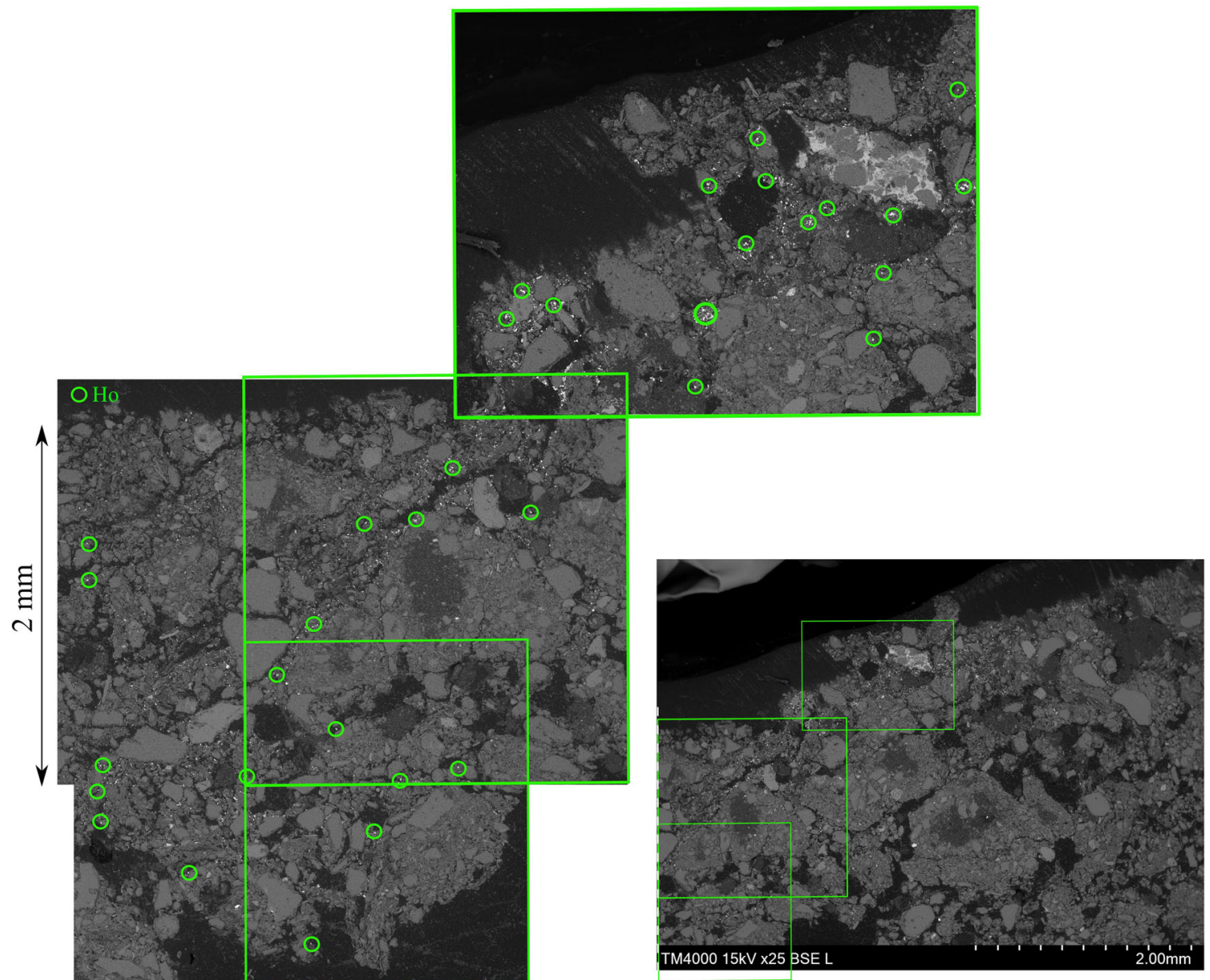

SEM image mosaic. In the uppermost image — based on the measured particles (23 Ho spectrum/ 28 total number of measurement) — we assumed that the unmeasured light particles were Ho particles. In a deeper section, all the potential Ho particles were measured. The reconstructed water movement direction indicates a clear leaching pattern. 


\section{Appendix 2}

SEM image mosaic of the upper 3 and $5 \mathrm{~mm}$ of the surface.

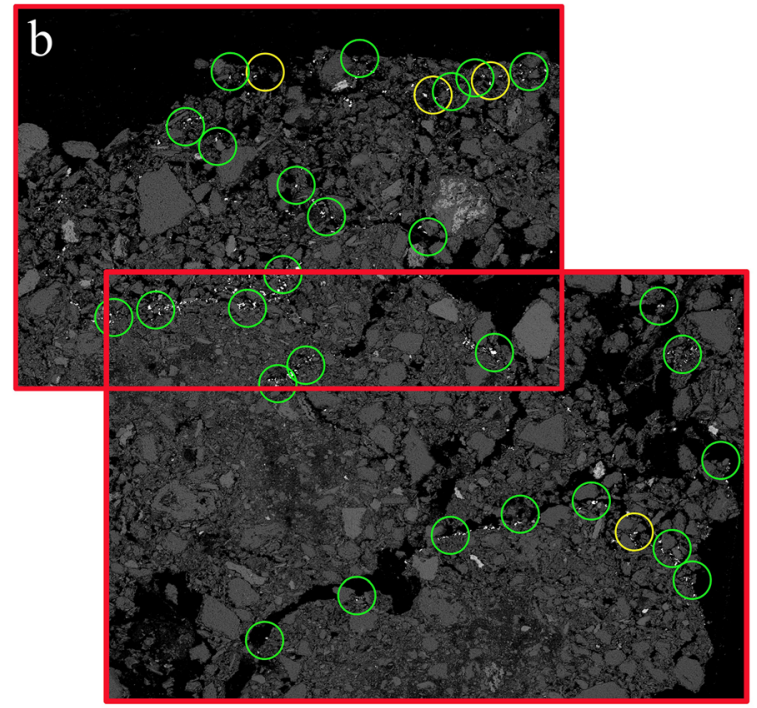

Legend

$\square$ image boundary

Ho

$\operatorname{Pr}$

$\bigcirc \mathrm{Sm}$

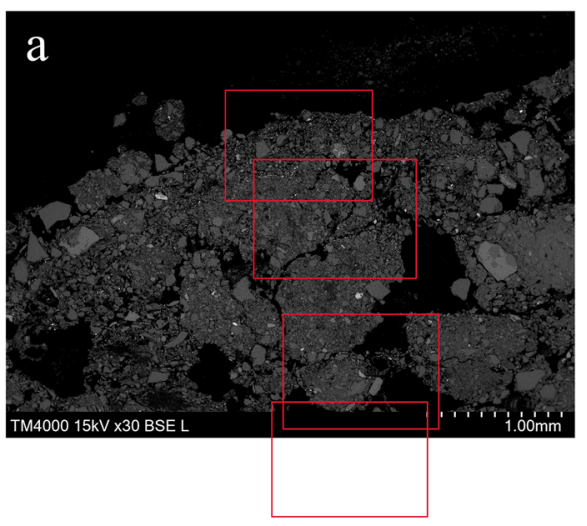

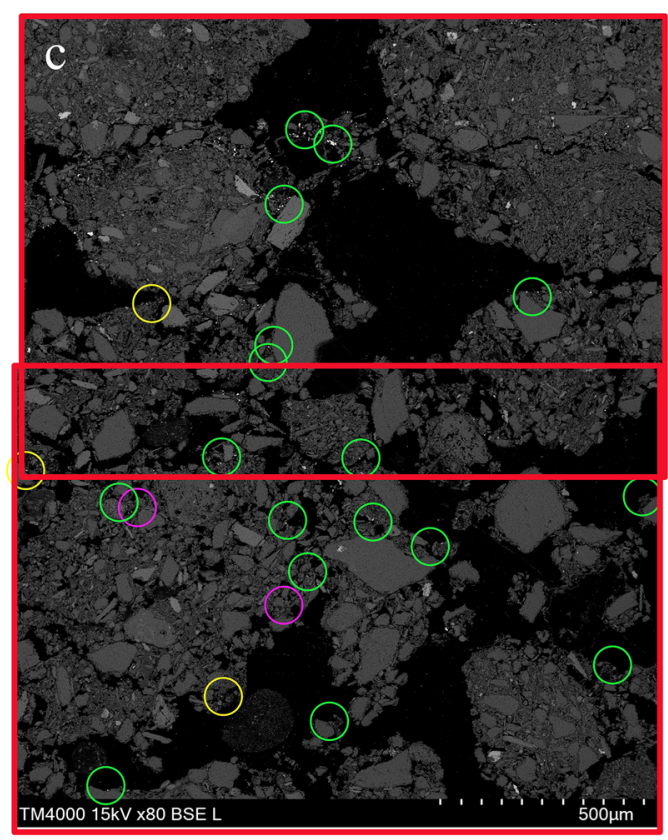


Open Access This article is licensed under a Creative Commons Attribution 4.0 International License, which permits use, sharing, adaptation, distribution and reproduction in any medium or format, as long as you give appropriate credit to the original author(s) and the source, provide a link to the Creative Commons licence, and indicate if changes were made. The images or other third party material in this article are included in the article's Creative Commons licence, unless indicated otherwise in a credit line to the material. If material is not included in the article's Creative Commons licence and your intended use is not permitted by statutory regulation or exceeds the permitted use, you will need to obtain permission directly from the copyright holder. To view a copy of this licence, visit http://creativecommons.org/licenses/by/4.0/.

\section{References}

Armstrong A, Maher B, Quinton J (2010) Enhancing the magnetism of soil: the answer to soil tracing? A Geophys Res Abstr 12, EGU2010-2805, EGU General assembly 2010

Assouline S, Ben-Hur M (2006) Effects of rainfall intensity and slope gradient on the dynamics of interrill erosion during soil surface sealing. Catena 66:211-220. https://doi.org/10.1016/j.catena.2006. 02.005

Balacco G (2013) The interrill erosion for a sandy loam soil. Int J Sediment Res 28:329-337. https://doi.org/10.1016/S10016279(13)60043-8

Castillo C, Pérez R, James MR, Quinton JN, Taguas EV, Gómez JA (2012) Comparing the accuracy of several field methods for measuring gully erosion. Soil Sci Soc Am J 76:1319-1332

Chen Y, Tarchitzky J, Brouwer J, Morin J, Banin A (1980) Scanning electron microscope observations on soil crusts and their formation. Soil Sci 130:49-55

Deasy C, Quinton JN (2010) Use of rare earth oxides as tracers to identify sediment source areas for agricultural hillslopes. Solid Earth:111118. https://doi.org/10.5194/se-1-111-2010

Di Stefano C, Ferro V, Porto P (1999) Linking sediment yield and caesium-137 spatial distribution at basin scale. J Agr Eng Res 74: $41-62$

Eltner A, Mulsow C, Maas H (2013) Quantitative measurement of soil Erosion from Tls and Uav data. Int arch Photogramm remote Sens spat. Inf Sci XL:4-6. https://doi.org/10.5194/isprsarchives-XL-1W2-119-2013

Flanagan DC, Nearing MA (1995) USDA water Erosion prediction project: hillslope profile and watershed model documentation. NSERL report no. 10, USDA-ARS National Soil Erosion Research Laboratory, West Lafayette, IN 47907-1194

Florinsky IV (2016) Digital terrain analysis in soil science and geology. Elsevier, London, p 486

Gilliot JM, Vaudour E, Michelin J (2017) Soil surface roughness measurement: a new fully automatic photogrammetric approach applied to agricultural bare fields. Comput Electron Agric 134:63-78. https://doi.org/10.1016/j.compag.2017.01.010

Gómez JA, Nearing MA (2005) Runoff and sediment losses from rough and smooth soil surfaces in a laboratory experiment. Catena 59:253266. https://doi.org/10.1016/j.catena.2004.09.008

Guzmán G, Barrón V, Gómez JA (2010) Evaluation of magnetic iron oxides as sediment tracers in water erosion experiments. Catena $82: 126-133$

Guzmán G, Quinton JN, Nearing MA, Mabit L, Gómez JA (2013) Sediment tracers in water erosion studies : current approaches and challenges. J Soils Sediments 13:816-833. https://doi.org/10.1007/ s11368-013-0659-5
Hairsine PB, Rose CW (1991) Rainfall detachment and deposition: sediment transport in the absence of flow-driven processes. Soil Sci Soc Am J 55:320. https://doi.org/10.2136/sssaj1991. $03615995005500020003 x$

Jakab G, Hegyi I, Fullen M, Szabó JA, Zacháry D, Szalai Z (2018) A 300year record of sedimentation in a small tilled catena in Hungary based on $\delta 13 \mathrm{C}, \delta 15 \mathrm{~N}$, and $\mathrm{C} / \mathrm{N}$ distribution. J Soils Sediments 18 : 1767-1779. https://doi.org/10.1007/s11368-017-1908-9

Juracek KE, Ziegler AC (2009) Estimation of sediment sources using selected chemical tracers in the Perry lake basin, Kansas, USA. Int J Sediment Res 24:108-125

Kabata-Pendias A, Pendias H (2001) Trace elements in soils and plants. CRC press, Washington, D.C, p 398

Kinnell PIA (2005) Raindrop-impact-induced erosion processes and prediction: a review. Hydrol Process 19:2815-2844. https://doi.org/10. 1002/hyp. 5788

Király C, Szalai Z, Varga G, Falus G (2019a) Homokkő szemcseméret- és szemcsealak-elemzése vékonycsiszolatokból Morphologi G3IDvel. Földtani Közlöny 14:25-34 In Hungarian with English abstract

Király C, Falus G, Varga G, Gresina F, Jakab G, Szalai Z (2019b) Granulometric properties of particles in middle Miocene sandstones from thin sections, Szolnok Formation, Hungary. Hungarian Geogr Bull (in Press)

Knaus RM, van Gent DL (1989) Accretion and canal impacts in a rapidly subsiding wetland. 3. A new soil-horizon marker method for measuring recent accretion. Estuaries 12:269-283

Laveuf C, Cornu S (2009) A review on the potentiality of rare earth elements to trace pedogenetic processes. Geoderma 154(1-2):112. https://doi.org/10.1016/j.geoderma.2009.10.002

Le Bissonnais Y, Bruand A, Jamagne M (1989) Laboratory experimental study of soil crusting: relation between aggregate breakdown mechanisms and crust stucture. Catena 16:377-392. https://doi.org/10. 1016/0341-8162(89)90022-2

Li H, Zhang X, Wang K, Wen A (2010) Assessment of sediment deposition rates in a karst depression of a small catchment in Huanjiang, Guangxi, Southwest China, using the cesium-137 technique. J Soil Water Conserv 65:223-232

Madarász B, Bádonyi K, Csepinszky B, Mika J, Kertész Á (2011) Conservation tillage for rational water management and soil conservation. Hungarian Geogr Bull 60:117-133

Metzger L, Robert M (1985) A scanning electron microscopy study of the interactions between sludge organic components and clay particles. Geoderma 35:159-167. https://doi.org/10.1016/0016-7061(85) 90028-X

Michaelides K, Ibraim I, Nord G, Esteves M (2010) Tracing sediment redistribution across a break in slope using rare earth elements. Earth Surf Process Landforms 35:575-587

Morgan RPC, Quinton JN, Smith RE, Govers G, Poesen JWA, Auerswald K, Chisci G, Torri D, Styczen ME (1998) The European soil Erosion model (EUROSEM): a dynamic approach for predicting sediment transport from fields and small catchments. Earth Surf Process Landf 23:527-544

Norton LD (1987) Micromorphological study of surface seals developed under simulated rainfall. Geoderma 40:127-140. https://doi.org/10. 1016/0016-7061(87)90018-8

Peng X, Zhu Q, Zhang Z, Hallett PD (2017) Combined turnover of carbon and soil aggregates using rare earth oxides and isotopically labelled carbon as tracers. Soil Biol Biochem 09:81-94. https://doi. org/10.1016/j.soilbio.2017.02.002

Pires LF, Borges FS, Passoni S, Pereira AB (2013) Soil pore characterization using free software and a portable optical microscope. Pedosphere 23:503-510. https://doi.org/10.1016/S1002-0160(13) 60043-0

Polyakov VO, Nearing MA (2004) Rare earth element oxides for tracing sediment movement. Catena 55:255-276. https://doi.org/10.1016/ S0341-8162(03)00159-0 
Polyakov VO, Nearing MA, Shipitalo MJ (2004) Tracking sediment redistribution in a small watershed : implocations for agro-landscape evolution. Earth Surf Process Landf 29:1275-1291. https://doi.org/ 10.1002/esp.1094

Polyakov VO, Kimoto A, Nearing MA, Nichols MH (2009) Tracing sediment movement on a semiarid watershed using rare earth elements. Soil Sci Soc Am J 73:1559-1565

Porto P, Walling DE, Callegari G (2011) Using 137Cs measurements to establish catchment sediment budgets and explore scale effects. Hydrol Process 25:886-900

Römkens MJM, Helming K, Prasad SN (2002) Soil erosion under different rainfall intensities, surface roughness, and soil water regimes. Catena 46:103-123. https://doi.org/10.1016/S0341-8162(01) 00161-8

Salles C, Poesen J, Borselli L (1999) Measurement of simulated drop size distribution with an optical spectro pluviometer: sample size considerations. Earth Surf Process Landf 24:545-556

Schoonover JE, Lockaby BG, Shaw JN (2007) Channel morphology and sediment origin in streams draining the Georgia Piedmont. J Hydrol 342:110-123

Shi P, Van Oost K, Schulin R (2017) Dynamics of soil fragment size distribution under successive rainfalls and its implication to sizeselective sediment transport and deposition. Geoderma 308:104 111. https://doi.org/10.1016/j.geoderma.2017.08.038

Snavely N, Seitz SM, Szeliski R (2008) Modelling the world from internet photo collections. Int J Comput Vis 80:189-210. https://doi.org/ 10.1007/s11263-007-0107-3

Stevens CJ, Quinton JN (2008) Investigating source areas of eroded sediments transported in concentrated overland flow using rare earth element tracers. Catena 74:31-36

Szabó J, Jakab G, Szabó B (2015) Spatial and temporal heterogeneity of runoff and soil loss dynamics under simulated rainfall. Hungarian Geogr Bull 64:25-34. https://doi.org/10.15201/hungeobull.64.1.3

Szalai Z, Szabó J, Kovács J, Mészáros E, Albert G, Cs C, Szabó B, Madarász B, Zacháry D, Jakab G (2016) Redistribution of soil organic carbon triggered by erosion at field scale under subhumid climate, Hungary. Pedosphere 26:652-665. https://doi.org/10. 1016/S1002-0160(15)60074-1
Valentin C, Bresson L (1992) Morphology, genesis and classification of surface crust in loamy and sandy soils. Geoderma 55:225-245

Walling DE, Schuller P, Zhang Y, Iroume A (2009) Extending the timescale for using beryllium 7 measurements to document soil redistribution by erosion. Water Resour Res 45:W02418. https://doi.org/10. 1029/2008WR007143

Wang L, Shi ZH (2015) Size selectivity of eroded sediment associated with soil texture on steep slopes. Soil Sci Soc Am J 79:917. https:// doi.org/10.2136/sssaj2014.10.0415

Wei S, Puling L, Mingyi Y, Yazhou X (2003) Using REE tracers to measure sheet erosion changing to rill erosion. J Rare Earth 21: $587-590$

Wischmeier WH, Smith DD (1978) Predicting rainfall erosion losses. USDA Agricultural Research Service Handbook 537

Xing B, Dudas MJ (1993) Trace and rare earth element content of white clay soils of the three river plain, Heilongiiang Province, P.R. China. Geoderma 58(3-4):181-199. https://doi.org/10.1016/00167061(93)90041-I

Zawisza B, Pytlakowska K, Feist B, Polowniak M, Kita A, Sitko R (2011) Determination of rare earth elements by spectroscopic techniques: a review. J Anal At Spectrom 26:2373-2390. https://doi.org/ $10.1039 / \mathrm{c} 1 \mathrm{ja} 10140 \mathrm{~d}$

Zhang XCJ, Wang ZL (2017) Interrill soil erosion processes on steep slopes. J Hydrol 548:652-664. https://doi.org/10.1016/j.jhydrol. 2017.03.046

Zhang XC, Friedrich JM, Nearing MA, Norton LD (2001) Potential use of rare earth oxides as tracers for soil erosion and aggregation studies. 65:1508-1515

Zhang XC, Nearing MA, Polyakov VO, Freidrich JM (2003) Using rare earth oxide tracers for studying soil erosion dynamics. Soil Sci Soc Am J 67:279-288

Zhu M, Tan S, Dang H, Zhang Q (2011) Rare earth elements tracing the soil erosion processes on slope surface under natural rainfall. $\mathrm{J}$ Environ Radioact 102:1078-1084. https://doi.org/10.1016/j. jenvrad.2011.07.007

Publisher's note Springer Nature remains neutral with regard to jurisdictional claims in published maps and institutional affiliations. 